\title{
Dying to know: Death during geological fieldwork
}

\author{
Marjorie D. Cantine ${ }^{1, *}$ \\ ${ }^{1}$ Department of Earth, Atmospheric and Planetary Science, Massachusetts Institute of Technology, Cambridge, MA, USA
}

\begin{abstract}
Fieldwork is a common element of geological research and education, and it involves many types of risk and reward. This study introduces a database of historical deaths during geological fieldwork to understand the causes of death, the most extreme consequence of physical risk, in the field. Most deaths in the field are unintentional. The database shows that vehicles and environmental risks from terrain, climate, and animals cause most unintentional deaths in the field. Most intentional deaths in the field result from conflict between geologists and community members, often related to land rights or political strife. Causes of geologist deaths in the field are compared to visitor deaths in the US National Parks and US workplace fatalities generally, revealing similarities and differences. This study highlights the central importance of site selection in managing risk during fieldwork. It also makes recommendations for how these data might inform teaching, research, and recruitment, especially regarding risk mitigation and student conceptions of workplace safety.
\end{abstract}

KEYWORDS geological fieldwork, field geology, field safety, workplace death, occupational hazard

\section{INTRODUCTION}

...[G]eology as an open-air pursuit affords an admirable training in habits of observation, furnishes a delightful relief from the cares and routine of everyday life, takes us into the open fields and the free fresh face of nature, leads us into all manner of sequestered nooks, [and] sets before us problems of the highest interest regarding the history of the ground beneath our feet...

from Geikie (1891)

$F^{\text {iid }}$ ieldwork encompasses activities from taking soil samples in an urban garden to SCUBA diving in an icecovered Antarctic lake or traditional bedrock mapping in rugged terrain. It forms the basis for much research in the Earth sciences. Historical views of fieldwork's importance within geology are reflected in statements that field study is "the ground truth for all Earth science investigations" (Ernst et al., 2006) and that "the geologist is made in the field" (Himus et al., 1955). Earth science undergraduate curricula reflect this perspective. One assessment found that 99 percent of US bachelor of science geology programs required field camp (Drummond and Markin, 2008). In the UK, 60 days in the field are required during accredited geology undergraduate degrees (Giles et al., 2020). Field

Copyright (c) 2021 by the Author(s)

doi: $10.2110 /$ sedred.2021.3.2

Manuscript submitted: 08/09/2021

Received in revised format: 09/09/2021

Manuscript accepted: 09/09/2021

*Corresponding author: mcantine@mit.edu; current address: Institut für Geowissenschaften, Goethe-Universität, Frankfurt am Main, Germany training is seen as critical to "the key transition from student to scientist" (quote from Feig, 2010). Nearly ninety percent of surveyed learners, instructors, and professionals agreed that fieldwork should be an "integral and required part of undergraduate programs" (Petcovic et al., 2014). After undergraduate training, fieldwork remains a central part of many Earth scientists' professional practice. Many geologists-though not all-spend some part of the year in the field collecting samples and making observations. Professional societies, including the Society for Sedimentary Geology (SEPM), incorporate field courses and excursions for trainees and professionals within their conference programs.

A growing literature explores making fieldwork safer and more accessible, especially for trainees and scientists with minoritized identities (Asher, 2001, John and Khan, 2018, Mol and Atchison, 2019, Stokes et al., 2019, Giles et al., 2020, Kingsbury et al., 2020, Abeyta et al., 2021, Cooperdock et al., 2021). The negative impacts of historical models of field camp and fieldwork on recruitment and retention of Earth scientists are increasingly discussed, with proposals for improving the student experience and identifying barriers to student success in the field (Stokes et al., 2019, Giles et al., 2020, Kingsbury et al., 2020, Abeyta et al., 2021, Cooperdock et al., 2021). If fieldwork remains a central part of Earth science curricula-as the vast majority of surveyed Earth scientists believe it should (Petcovic et al., 2014)-then doing fieldwork well, safely, and in a way that appeals and is accessible to a broad swathe of students is a critical step in recruiting and retaining a large and diverse Earth 
science workforce: an important and ongoing effort (Stokes et al., 2015, Bernard and Cooperdock, 2018, Wilson, 2019, Stokes et al., 2019, Easterling, 2020). Perceptions of future workplace safety and working conditions likely shape student selection of a major and profession (Duffy et al., 2016, Ma et al., 2021). For geologists who perform fieldwork as part of their professional practice, doing fieldwork well and safely is also of obvious interest. All these factors motivate the collection of data about safety and risk during geological fieldwork.

To that end, this study explores one facet of risk in the field: the risk of death, the most extreme consequence of physical harm. By studying the deaths of fellow geologists in the course of fieldwork, we can gain a more accurate understanding of the sources of physical risk in the field, allowing us to communicate about the dangers of fieldwork, anticipate physical risks, and prevent deaths. This practice also allows us another way to honor and remember the lives and contributions of our lost colleagues.

Earth and planetary scientists of all ages and specialties, including pivotal figures like Alfred Wegener and Eugene Shoemaker, have died during fieldwork. Are there patterns in who dies in the field? What are the causes of deaths during fieldwork? How might these data shape our approach to living, working, and teaching in the field? And how can we honor, remember, and learn from the deaths of our colleagues and friends?

\section{BUILDING A DATABASE}

To begin answering these questions, a database was built covering deaths that occurred during geological fieldwork from January 1, 2000 to June 30, 2021. The definition of geological fieldwork used was the scientific study of geological phenomena outdoors, whether that activity occurs for teaching or research or economic gain. The time interval was selected because online records prior to 2000 were more likely to be incomplete. One benefit of this relatively recent time window is that the deaths included reflect contemporary issues, practices, and risks relevant to ongoing fieldwork. The database is available in the supplementary material associated with this paper, as well as at https://github.com/mcantine/field-deaths.

Community acknowledgement The author respectfully acknowledges that readers may know people included in the database, and that it may be jarring to encounter deceased colleagues in this context. The author invites readers to share the names and stories of Earth scientists who have not been included in this study, or to contact the author to correct the database where errors are found.

\section{Gathering data}

Reports of deaths came from news sites accessed through Google Search and combinations of search terms including geologist, geophysicist, death, attack, drowning, field, fieldwork, and fall. The first 1,000 results on Nexis-Uni Negative News (both Business and Personal Negative News), a news source aggregator, for geologist death was used. Online memorials were also used to find cases to add to the database (Conniff, 2021, Lab Safety Institute, 2021), though other news articles were used to confirm these reports. The majority of cases (49 of 69) included in the database were found this way. During the submission process, the editor identified two deaths described in Korean-language news sources, and these were also added to the database.

Fatality reports also came from the Occupational Health and Safety Administration (OSHA) Fatality and Catastrophe Investigation Summaries (Occupational Safety and Health Administration, 2021). OSHA is a US regulatory agency responsible for assuring safe and healthy work conditions for working people. OSHA's jurisdiction extends to most of the US private sector, though some private sector workplaces fall under the jurisdiction of other regulatory agencies, like the Coast Guard, Department of Energy, or the Mine Safety and Health Administration. Public sector workplace safety at the state and local level sometimes falls under OSHA jurisdiction, and all federal workplaces (e.g., the US Geological Survey or the Environmental Protection Agency) fall under OSHA jurisdiction. Over the study period, more than 35,000 workplace fatality events and catastrophes (events which cause the deaths of 3 or more workers) occurred (Occupational Safety and Health Administration, 2021).

OSHA uses Standard Industrial Classification (SIC) and North American Industry Classification Scheme (NAICS) numbers to code fatality reports by industry sector. These codes were used to search for cases of death during geological fieldwork. All results for deaths coded for Professional, Scientific, and Technical Services (NAICS code 54), Education (NAICS code 61, SIC code 82), Administration of Environmental Quality Programs (NAICS code 924), Support Activities for Mining (NAICS code 213), Engineering, Accounting, Research, Management, And Related Services (SIC code 87), Museums, Art Galleries, And Botanical And Zoological Gardens (SIC code 84), Administration Of Environmental Quality And Housing Programs (SIC code 95), Metal Mining (SIC code 10), Coal Mining (SIC code 12), Mining And Quarrying Of Nonmetallic Minerals, Except Fuels (SIC code 14), Oil and gas field exploration services (SIC code 1382), and Oil and gas field services not elsewhere classified (SIC code 1389) over the study interval were examined, as were all results for OSHA-identified keywords animal, animal bite, avalanche, bee sting, boulder, bus, earthquake, frozen, heat, heat exhaustion, helicopter, icy, intoxicated, inexperience, lost balance, suicide, uneven ground, unstable soil, workplace violence, and walking surface, as were all OSHA fatality abstracts using the words hiking, survey, outdoor, geologist, geophysicist, SCUBA, hike, geological, geology, university, college, professor, or sample. OSHA abstracts are very brief. Where OSHA data duplicated or contradicted information also found in news articles, the more detailed sources were used. 18 cases included in the database were found this way. 


\section{Coding data}

For each death, the news source, the geologist's name if available, and apparent gender were recorded. Apparent gender was based on pronouns used within the news source, or first name if no pronouns were used; where unclear, gender is marked as unknown. This approach reflects the limitations of the source material. Other data were collected, including any data, like age, student status, or career stage that could illuminate geologists' position in their workplace hierarchies; the geologists' employment sector; and cause of death. The database also contains both a short and long description of each incident.

\section{Comparisons}

Other cause-of-death databases offer comparisons for identifying key trends in the risks of geological fieldwork compared to similar activities. This study uses the National Parks Service (NPS) CY 2014-2016 Visitor Mortality Dashboard (National Parks Service, 2017) and the Bureau of Labor Statistics (BLS) 2019 Census of Fatal Occupational Injuries (CFOI) (Bureau of Labor Statistics, 2020) as comparisons. These are the most recent data available for their respective sources. The NPS data provide comparison to deaths during outdoor recreation and the BLS data document workplace fatalities nationally.

The NPS data codes each death as intentional (deliberately caused by a person), medical (e.g., a stroke or heart attack), or unintentional (neither deliberately caused nor the result of a medical event). These categories cover 93 percent of all NPS visitor mortalities. The BLS CFOI categorizes each non-medical death as resulting from transportation incidents; violence and other injuries by persons and animals; contact with objects and equipment; falls, slips, and trips; exposure to harmful substances or environments; or fires and explosions. These categories account for more than 99 percent of all deaths in the BLS CFOI. To facilitate comparison between these datasets, each geologist death was also coded using the same categories.

\section{Excluded data}

Some deaths were identified but excluded from further analysis. Although geologists' deaths at construction sites, oil and gas wells, and mines represent a substantial proportion of total geologist workplace deaths, these deaths are excluded because construction sites, oil and gas fields, and mines pose hazards to workers (e.g., trench collapse; heavy machinery) that are not generalizable to typical geological fieldwork. The deaths of exploration geologists and economic geologists away from mines, as well as deaths during geophysical or seismic surveys, are included.

Deaths that occurred during other forms of scientific research are generally not included. However, the Earth sciences are inherently interdisciplinary and have porous boundaries. This is reflected in the database, which includes, for example, a biologist who collected soil samples during fieldwork associated with a mining prospect, and an ecologist employed by the US Geological Survey.
The final database includes 69 deaths of Earth scientists that occurred during fieldwork. To document the process of inclusion and exclusion taken here, the database includes 29 additional cases of deaths not included in further analysis, along with a rationale for their exclusion.

\section{Completeness of the dataset}

The BLS CFOI documents 19 total deaths in the categories of Environmental scientists and geoscientists, Geological and petroleum technicians, and Environmental science and protection technicians, including health from 2003-2018 (the most recent data available with this level of granularity) (Bureau of Labor Statistics, 2019). The US population is roughly 5 percent of the world population; making the (admittedly over-simplified) assumption that US geologists thus also make up 5 percent of global geologist on-the-job deaths, this implies approximately 500 deaths by geologists and associated professionals around the world during the study interval. This study's focus on deaths in the field, not in the laboratory, on construction sites, during oil and gas extraction, or in mines then reduces the maximum possible database size. This database is also different from BLS CFOI data because it includes student deaths, not only employee deaths. Despite this difference, this rough estimation suggests that the current database of 67 deaths likely covers many, though not all, deaths during geological fieldwork over the study period.

The most serious gap in the database is likely its undersampling of global deaths due to its reliance on Englishlanguage sources. This database is further biased towards US deaths due to its use of data from the US federal government. The database is also likely to oversample violent or unusual deaths, such as those by homicide, animal attack, or helicopter accident, because these deaths likely receive more news coverage than other deaths. The database is also likely to be more incomplete in the early part of the period considered, due to the increasing use of the Internet over the study window. A comparison of this database with other databases of volcanic hazard deaths (Brown et al., 2017) and brown bear attacks in Russia (Kudrenko et al., 2020) suggests it has covered at least these two hazards comprehensively.

Inequalities and differences in education, training, and opportunity result in known differences in on-the-job fatality rates for workers of different racialized groups (Leeth and Ruser, 2006). However, race is not reported in the database, or in many of the sources used to construct it, and so this analysis does not examine variation in risk between racialized groups.

This database is also incomplete in that it only considers death. Death is not the only form of physical harm that might occur during fieldwork, nor is physical harm the only type of harm. This initial work is best read as a complement to other recent work exploring ways to improve the field experience (e.g., Clancy et al., 2014, Giles et al., 2020, Cooperdock et al., 2021, Abeyta et al., 2021). This database is also incomplete in that it focuses on harm to 
geologists or Earth scientists from geological fieldwork. Geologists may cause harm to local community members during geological fieldwork, but this type of harm is not captured by the database.

Completeness is a worthy goal. Our community can do more to commemorate fallen geologists and to document and learn from their deaths. Even incomplete, this initial database provides us with useful information for shaping how we teach and research in the field.

\section{RESULTS}

This analysis shows that deaths during geological fieldwork are mostly unintentional (Figure 1A). Vehicle and helicopter crashes, animal attacks, drownings, and falls account for 80 percent of unintentional deaths (Figure 1D). Neither youth nor experience guarantee safety in the field; the database includes people who were between seventeen and eighty years of age at the time of their death. Students, faculty, management, and laborers are all represented. Ten of the eleven students in the database died due to unintentional causes, largely the result of accidents and mishaps.

Most geologists who die in the field are men (Figure 1B). Deaths are subequally distributed among the academic, private, and government sectors, with the private sector encompassing 36 percent of all deaths (Figure 1C). If geologist deaths within construction sites and mines were included in this analysis, the share of deaths from the private sector would be even greater.

To assess similarities in causes of death, multiple analysis of variance (MANOVA) was performed comparing causes of death between this database and the NPS and BLS datasets (Figure 2). Across the broad categories of intentional, unintentional, medical, and undetermined deaths, variance in the proportions of geologist deaths and NPS visitor deaths was not statistically significantly different. However, the broad similarity in rates of intentional death between NPS visitors and geologists conceals an important difference. For NPS visitor fatalities, intentional deaths are 95 percent deaths by suicide (National Parks Service, 2017). None of the geologist deaths in the database were deaths by suicide. Within the broad categories of transportation, violence, falls, exposure, and contact, geologist deaths and BLS deaths are statistically distinct $(\mathrm{p}=0.02)$, corresponding to differences in the proportions of deaths by violence, falls, and contact with objects or equipment (Figure 2G).

\section{DISCUSSION}

\section{Comparison across datasets}

Comparison of the database to NPS visitor mortality and BLS occupational fatality data shows that all three datasets show a gender gap in deaths, with males or men making up more than three-quarters of deaths in each case (Figure 2).

Unintentional causes of death between geologists and NPS visitors are broadly similar, suggesting that intrinsic features of remote natural environments pose similar physical risks to both groups. Vehicle accidents caused roughly 30 percent of unintentional deaths for both geologists and NPS visitors, and drowning and falls were in the top five causes of unintentional death for both groups (National Parks Service, 2017) (Figure 1D). Statistically significant differences in causes of death between the field deaths database and the BLS 2019 CFOI ( $p=0.02$; Figure $2 \mathrm{C}, \mathrm{G}$ ) are seen in the varying proportion of deaths by violence, falls, and contact. This finding indicates that the causes of death in the field are distinct from the causes of death across US workplaces. Perhaps surprisingly, given the steep terrain of many field sites, a smaller proportion of geologist deaths follow a fall, trip, or slip than for US workplace fatalities. As documented by the database, a greater proportion of geologist deaths result from violence than for workplace fatalities nationally, though this may reflect more extensive news coverage of geologist fatalities that occur in this manner.

\section{Death and sex/gender}

Field deaths are disproportionate with respect to sex/gender (Figure 2A). The gender gap in geologist fatalities is observed across academic (14 men of 18 total deaths; within student deaths, 7 of 11), government (19 men of 22 total deaths, with unknown gender in 1 case), and private sector roles (20 men out of 24 total deaths, with unknown gender in 1 case). Every cause of death was also dominated by men, including homicide (11 of 13 deaths), medical events (9 of 9 deaths), and unintentional deaths (39 of 47 deaths).

The gender gap in geologist deaths could reflect a broader gender gap in geology. Since 2008, about 30 percent of those working as environmental scientists and geologists have been women and about 40 percent of geology degrees have gone to women since the early 2000s (Wilson, 2019). (The presence and size of a gender gap specifically within the set of geologists who perform fieldwork is not clear; it could be conservatively assumed that such a gender gap exists and is of a similar magnitude as the broader geology gender gap.) The gender gap in workplace fatalities is also consistently observed across all workplaces, with fatalities claiming mostly men (Figure 1C). (Hersch, 1998, Leeth and Ruser, 2006, Bureau of Labor Statistics, 2019). Although men, on average, work more physically dangerous jobs than women, analysis suggests that even when men and women work the same job, men still have a greater risk of death (Leeth and Ruser, 2006). This phenomenon has been attributed to gendered behaviors around risk (Leeth and Ruser, 2006, Phillips, 2006). Disproportionate male deaths in the National Parks (Figure 1B) contrast with visitor data showing relative gender parity both across all sites served by the National Parks Service (Pacific Consulting Group, 2019) and at an individual park (Liang et al., 2020) (though data is limited). This suggests that differences in behavior, rather than differences in visitation, drive disproportionate deaths in the Parks. Disproportionate male geologist deaths may not only reflect the known gender gap in geological careers, but also 

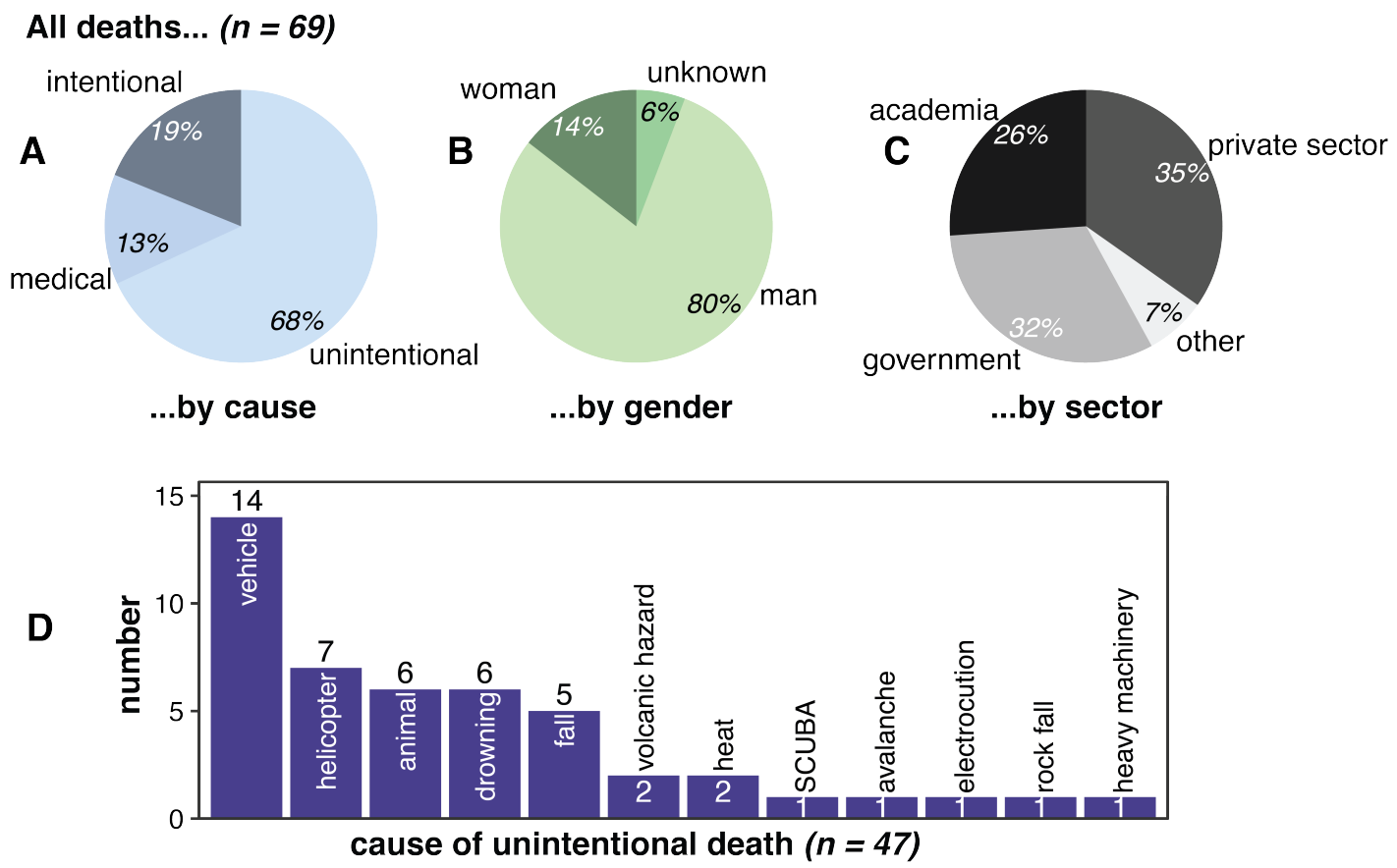

Figure 1: Results from the database. A. Causes of death. B. Breakdown of deaths by gender. C. Deaths by sector. D. Causes of unintentional death within the database.

gendered differences in behaviors around risk, as has been suggested in other professions (Phillips, 2006, Leeth and Ruser, 2006).

\section{Spotlight on intentional death}

Less than 20 percent of deaths in the geologist database were intentional deaths $(n=13$ of 69 , Figure $1 A)$. All intentional deaths within the database were homicides (i.e., no deaths by suicide that otherwise matched the search parameters were found). Because homicides attract news attention, this may be an overestimate of their relative proportion.

In no case included in the database was death reported to result from violence between members of a field team. Overall, these data suggest that intentional death is more likely to result from interactions with people outside the field team than within the field team. This contrasts with sexual violence in the field, in which most perpetrators are within the scientific field team (Clancy et al., 2014).

Most geologists who died by homicide (12 of 13) were geologists working for mineral resource or oil and gas firms outside of the US. The deaths of these victims sometimes followed disputes over land or mining rights (e.g., the death of Papua New Guinean geologist Terry Win Kilya, who was conducting mineral exploration studies in a disputed area of Papua New Guinea). In other cases, these deaths occurred in locations in which armed militia groups were active. Sometimes, the kidnapping and murder of a geologist was an explicitly political action (e.g., the killing of Polish geologist Piotr Stańczak by the Taliban in Pakistan). These cases highlight the role of site selection in determining risk. Field site selection for teaching and, to a smaller but still substantial degree, academic research, is more flexible than site selection for mineral extraction. The small proportion of academic deaths by homicide suggests that academic groups are leveraging this flexibility to minimize the risk of death by homicide, and they should continue to do so. Resources for evaluating site selection might include government reports, like the US Department of State travel advisories, and the advice of local collaborators.

The single homicide within the database that did not conform to this larger pattern involved a graduate student killed in an act of random violence by a stranger during field mapping during an internship in the US (the murder of Alyssa Heberton-Morimoto in 2007). Implications for student fieldwork are further discussed below.

\section{Planning for student fieldwork}

Understanding the potential risks of fieldwork for students is of special importance for Earth science educators. Causes of deaths for students $(\mathrm{n}=11)$ included animal attack (2), homicide (1), falls or rock-fall (3), drowning (1), probable heat exposure (1), and vehicle collision (3). Four of the eleven students in the database were alone at the time of their death; requiring the buddy system for participants and reminding students of their responsibility for each other may help mitigate risk as well. Vehicles cause many unintentional deaths in the field, yet are a widely used and important element of most educational field trips-and likely to remain so. Seatbelt use, driver training, minimizing time driving in poor or dark conditions, providing participants with high-visibility gear for roadside work, and continuing to avoid the use of fifteen-passenger vans 
How do geologist deaths compare?

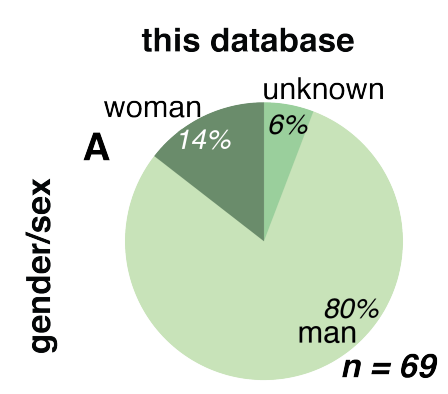

National Parks Service

Visitor mortality, 2014-2016
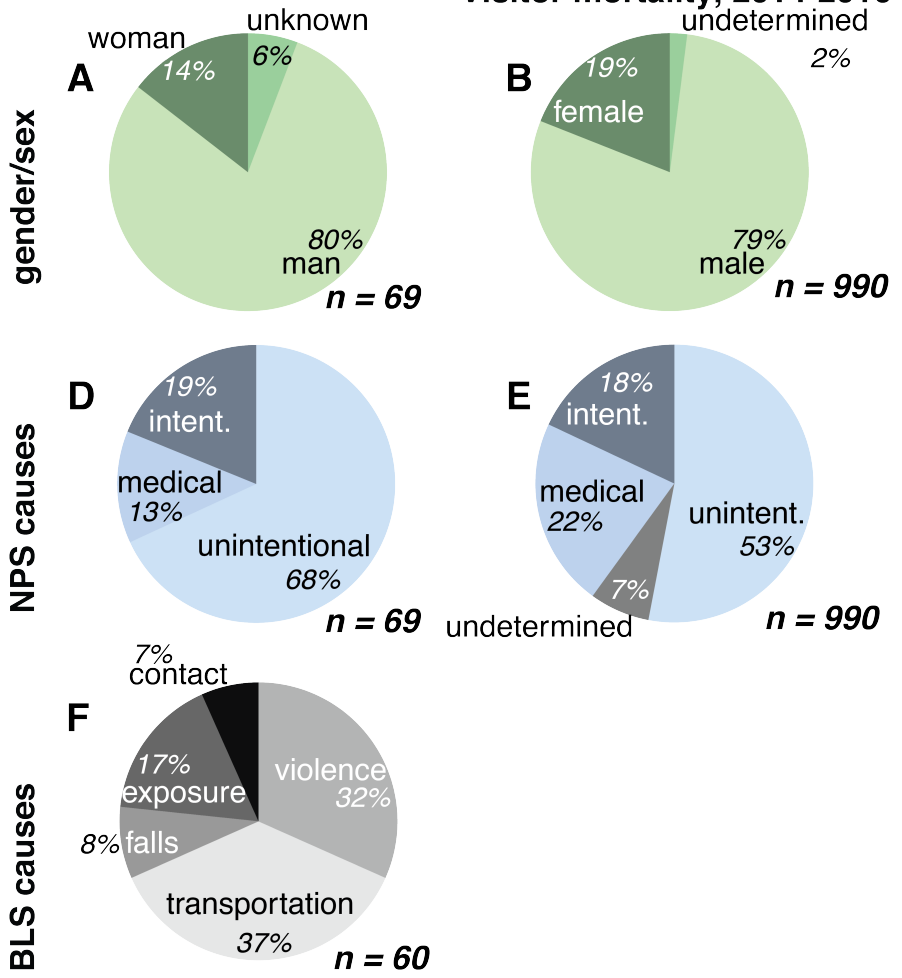

Bureau of Labor Statistics

US occupational fatalities, 2019

woman

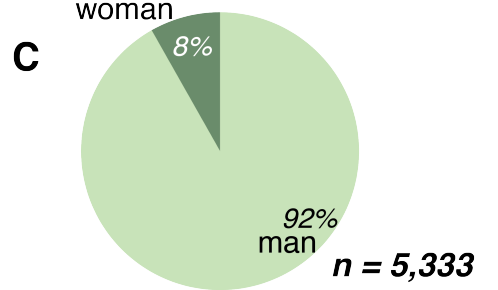

Figure 2: Comparison of the database with other fatality datasets. A. Deaths by gender in this database. B. Deaths by sex in the National Parks Service (NPS) CY 2014-2016 Visitor Mortality Dashboard. C. Deaths by gender in the Bureau of Labor Statistics (BLS) 2019 Census of Fatal Occupational Injuries (CFOI). D. Causes of death in this dataset, using the same categorization as the NPS Visitor Mortality Dashboard. E. Causes of death in the National Parks Service (NPS) Visitor Mortality Dashboard. F. Causes of death in this dataset, using the same categorization as the BLS CFOI. G. Death by cause in the BLS 2019 CFOI. Note: the use of "woman," "man," "female," and "male" for NPS and BLS data reflect their use in the original sources. Figure 2F and 2G add to 101 percent due to rounding.

are all best practices for mitigating this risk.

Probably the single largest choice in terms of its impact on all other safety decisions in the field is the selection of field site. Field sites with substantial political unrest or extreme environmental challenges should be avoided in educational contexts. Many student deaths resulted from environmental factors (animal attack, falls or rock-fall, drowning, and heat exposure)-all factors related to the inherent qualities of a field site. Although outdoor environments all have some inherent and unavoidable physical risks, they vary greatly in the degree and type of risk they pose. Substantial physical risks can be eliminated or mitigated through thoughtful choices by instructors, trip planners, and participants. Such decisions could include selection of a route that avoids river crossings; forgoing the use of helicopters; choosing temperate seasons for fieldwork; requiring students to use the buddy system; or insisting on seatbelt use and paying close attention to driving conditions. Field camps and courses should balance learning goals with risk in selecting field sites, and should avoid placing students in higher-risk settings when lower-risk settings satisfy pedagogical objectives.

All field courses can and should take time to highlight the inherent physical risk of outdoor environments and prepare students to work safely in them, without necessarily assuming previous experience in the field. By openly discussing both potential risks and mitigation strategies, both verbally and within a printed field guide, trip planners may be able to further mitigate risks and encourage all trip participants to engage thoughtfully with risk. In addition to encouraging safety, trip leaders can discourage risk by identifying reckless behavior and providing consequences for it. This can help to prevent the culture of a field team from valorizing needless risk-taking. Students and trip participants can also use this dataset to inform decisions that empower and protect themselves, like taking a swimming class, learning wilderness survival techniques, or using seatbelts consistently.

The National Association of Geoscience Teachers publishes a useful resource exploring many facets of field safety to help trip leaders plan (Tewksbury and Tewksbury, 2004). For example, field trip planners can build pre-departure 
safety plans, which can include information about likely risks in the field or information like the location of the nearest hospital, and contact information for local landowners and community members. Lessons in changing flat tires, driving vehicles with manual transmission, or wilderness first aid can be included in field education, providing students with both a greater sense of agency and control over their environment and useful skills for present and future fieldwork. These and other recommendations for minimizing physical risk while leading trips with students are shown in Figure 3. Recommendations also include developing robust risk management policies at the department level; considering personal liability insurance for trip leaders; and working with a redundancy mindset, in which trip leaders communicate to participants what they need to know to be able to respond and react to an emergency without them (Tewksbury and Tewksbury, 2004). Educators teaching introductory classes should not necessarily assume that their students have any relevant outdoor experience, and can make time during lectures, lab, or field exercises to demonstrate and discuss safety practices-from carrying water and staying hydrated, to navigating hills and slopes, to choosing appropriate footwear that fits well.

Students may not only fear physical risk from the natural environment, but also interpersonal violence, a concern enhanced by the unfamiliar surroundings and remoteness of many field sites (Clancy et al., 2014, Anadu et al., 2021). This database only considers the risk of death, and not all forms of non-fatal injury, so its consideration of interpersonal violence is necessarily incomplete. However, some generalizations about interpersonal violence leading to death can be made. Most homicides in the database involve economic and exploration geologists working in areas with conflict. The single student homicide included in the database was an act of random violence from an itinerant stranger, not a local landowner or community member. It occurred during a research-focused mapping activity during an internship rather than during a class. The student was alone when she was attacked, although she and another geologist used walkie-talkies. Educators should not dismiss student concerns about stranger violence and may be able to mitigate this risk through the buddy system. Trip leaders can also contextualize this type of violence as highly unusual in the context of standard student fieldwork. Educators can address both the possibility of conflict and concerns about conflict with landowners or local community members by introducing themselves and trip participants to local stakeholders and ensuring that trip members have clothing and identification that establishes them as part of a university or professional group (Cooperdock et al., 2021).

Local law, custom, and tradition can impact fieldwork in a number of ways, and these impacts on educational trips are particularly worth considering. One example is the shared use of public land by geologists and hunters. Anecdotes describing unexpected encounters between field geologists and local hunters are not uncommon. Though no death in the database results from such an encounter, it is not hard to imagine an accident occurring. Geologists can consider who else might be using land, be aware of hunting season dates, communicate with local game wardens, and wear high-visibility clothing where appropriate. The impact of some other local laws and customs, like those concerning homosexuality or modesty, may be more difficult to mitigate. Prohibitions like these can impact students' sense of safety and educational experience. Though no death currently included in the database is known to have resulted from these factors, such issues might contribute to conflict between the field team and the local community. The best practice for undergraduate education would be to choose field sites that can welcome a diverse group of students, and to anticipate and prepare for potential points of conflict between the field team and community members.

The data presented here can help trip leaders speak to their students about sources of physical risk in the field. However, physical safety is not the only area of concern for students. In addition to assuaging concerns about physical risk, instructors can remain curious, and seek to understand if a student is also concerned about other challenges and risks, which might include, for instance, financial strain (Abeyta et al., 2021), discrimination (Anadu et al., 2021), harassment and assault (Clancy et al., 2014), accessibility (Asher, 2001, Stokes et al., 2019), physical discomfort (Anadu et al., 2021), lack of appropriate field equipment (Abeyta et al., 2021, Anadu et al., 2021), or toilet facilities (Greene et al., 2020). To ensure a two-way flow of information between participants and planners, trip organizers can collect pre-trip questionnaires, with an optional anonymous component, that ask for medically necessary information as well as participants' experience, concerns, and preparation for the field. This can help organizers ensure that all participants will have the equipment, food, and resources needed to make the most of the field experience.

\section{Physical risk, decent work, and student career planning}

Two current goals of the Earth science community are to diversify the Earth science community and to increase the total amount of undergraduates studying Earth science (Bernard and Cooperdock, 2018, Wilson, 2019, Stokes et al., 2019, Easterling, 2020, Cooperdock et al., 2021). Can these data be used to further those goals?

These data can help educators speak to student concerns about workplace safety, which likely inform student selection of a major and career path. Students, especially students from marginalized backgrounds, often understand undergraduate education largely as career preparation for work that is more desirable than that available without undergraduate study (da Silva Cardoso et al., 2013, Blackwell and Pinder, 2014, Zavala, 2014, Tieken, 2016, Ma et al., 2021). What makes work desirable is summarized in the concept of decent work: work that has safe working conditions, both physically and interpersonally; allows free time and rest; is consistent with familial and social values; and provides fair wages and access to health care (Duffy et al., 


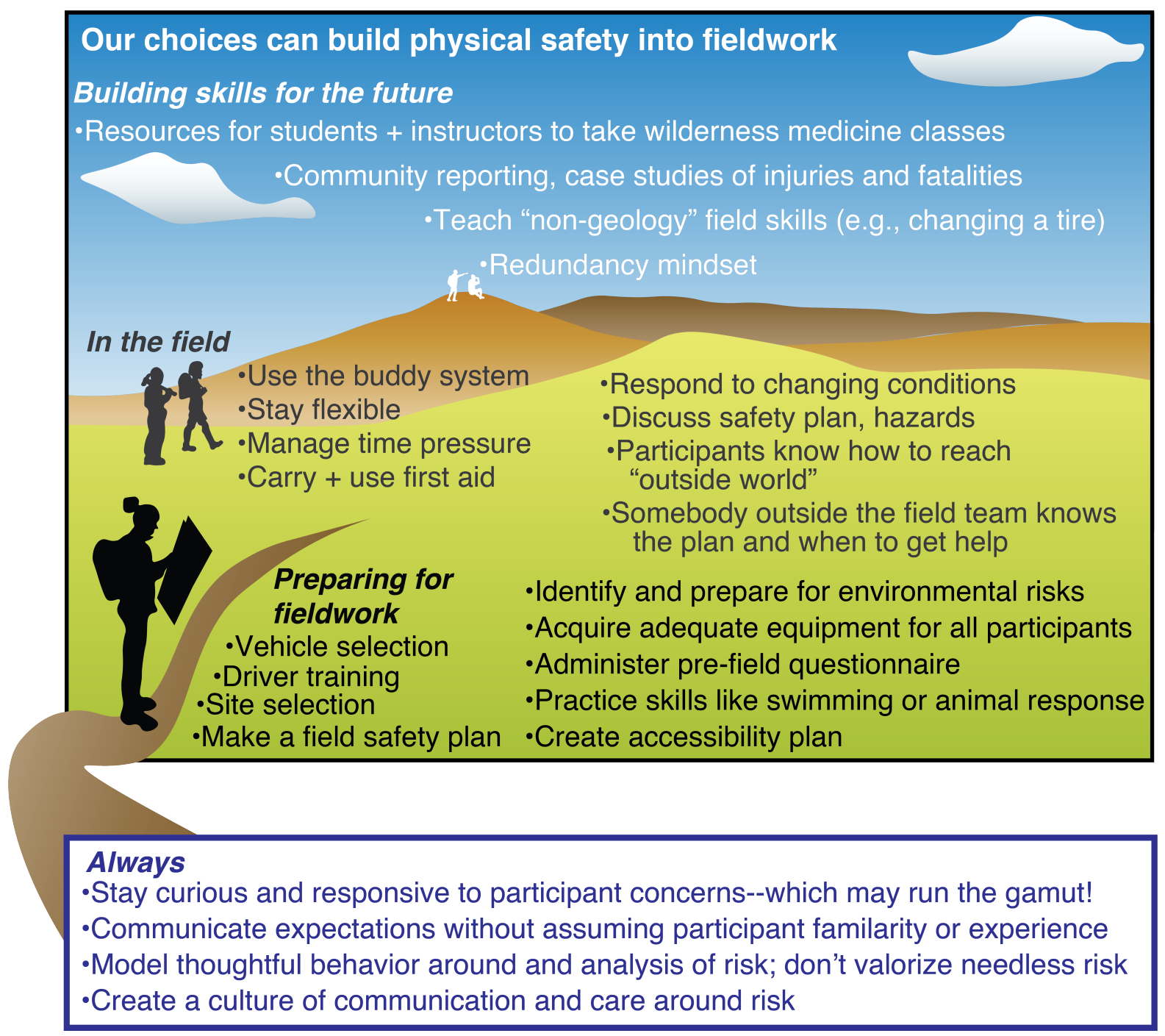

Figure 3: By making thoughtful choices, we can manage risk and increase physical safety for trip participants in the field. Risk management begins during preparations for the field, continues in the field, and includes empowering budding geologists to develop a safety skill set. This list of recommendations is expanded and adapted from Tewksbury and Tewksbury (2004).

2016). Students considering a career in the Earth sciences are in part likely evaluating if this path will provide them with safe physical working conditions both during and after their education. Educators can use data from this study to highlight that some physically risky elements of fieldwork can be avoided or seriously mitigated by planning. They can then describe to students how they incorporate risk mitigation into their trip design to normalize a safety culture (Cooper, 2000). By emphasizing the ways that the Earth sciences can provide students with decent work, educators may be able to reach a larger and more diverse group of students.

Educators can also highlight the fact that many career paths in the Earth sciences require little, or no, fieldwork, and that the physical risks associated with Earth science careers varies. Fatal injury rates are calculated as the total fatal injuries per total hours worked annually per 100,000 full-time equivalent workers, and provide a basis of fatality risk comparison between different jobs (Bureau of Labor Statistics, 2020). Although geologists and Earth scientists may work at construction sites, mines, or oil and gas fields that are relatively high-risk, reflected in a high fatal injury rate (12.9) of construction and extraction occupations (Bureau of Labor Statistics, 2020), these are far from the only options available for geologists. Emphasizing the range of careers possible for an Earth science graduate can be a powerful recruiting tool, helping students appreciate their ability to select a career from a broad set of options (Stokes et al., 2019).

Fatality data offer additional perspective on the relative occupational hazard of scientists in the US and on campuses. Of the 60 OSHA abstracts returned for Colleges, Universities, and Professional Schools (SIC code 8221), roughly one-third of cases relate to construction workers, janitors, electricians and laborers dying in the course of their own contributions to universities and colleges. About 
one-twelfth of cases are connected with laboratory accidents across all disciplines (Occupational Safety and Health Administration, 2021). The average 2019 fatal injury rate for those in Life, physical, and social science occupations was 1.1; for the entire American workforce, the rate was 3.5 (Bureau of Labor Statistics, 2020). There are certainly physical risks associated with scientific work, whether in the field or laboratory. In the US, data show that scientists experience a lower rate of fatal occupational injuries than the average American worker. This may be useful context for students concerned about occupational hazards in scientific careers.

\section{Next steps}

This dataset does not include information about non-fatal physical injuries. These are undoubtedly more common than fatal injuries in the field, but data about these events are less accessible, especially for student injuries. This lack of data makes a full analysis of physical risk leading to injury and death difficult, yet such analyses can be very useful (e.g., see Schussman et al., 1990 for an epidemiological treatment of injury and death during mountaineering and the specific skills, practices, and tools that contributed to or prevented fatalities). Building out new datasets, both qualitative and quantitative, regarding non-fatal physical harm, other forms of interpersonal harm, and the factors that might contribute to or mitigate severity of harm (e.g., duration of trip, remoteness of field site, team structure, codes of conduct) are obvious next steps for future research.

After more than a year of largely remote classes and limited or virtual fieldwork due to the COVID-19 pandemic, educators, students, and researchers in 2021 can appreciate the unique insights and experiences made possible by inperson fieldwork. Although some physical risks inherent to living and working outside cannot be entirely removed, human behavior and choices can either minimize or increase them. Accurately accounting for, understanding, and preparing for physical risk in order to prevent tragedy during education and research is the shared responsibility of our scientific community and the individual responsibility of field scientists and educators as we contribute to the project of studying our Earth.

\section{CONCLUSIONS}

1. Understanding the causes of death, the most severe consequence of physical risk, can improve risk management during fieldwork for students and researchers through planning and preparation.

2. Most geologists who die in the field are men. This may reflect an underlying gender gap in Earth science careers, and/or sex/gender differences in behavior around risk.

3. Homicide in the field typically occurs in association with disputed territory, political unrest, or competing economic interests, and with conflict between geologists and people outside the field team, rather than within. This distinguishes homicide from sexual violence in the field, which typically occurs within the field team.

4. Vehicle accidents, helicopter crashes, animal attacks, drownings, and falls caused 80 percent of unintentional deaths in this database. These and other causes of unintentional deaths can be mitigated through choices and planning before and in the field.

5. Students may critically evaluate physical safety in the field as an important element of their search for decent work. Educators can incorporate workplace safety in their discussion of geoscience careers, and demonstrate safety culture in their planning of field trips.

\section{DATA AVAILABILITY}

Data and code used in this analysis are available for download at https://github.com/mcantine/field-deaths. Readers are invited to contact the author with corrections and additions to the database.

\section{ACKNOWLEDGMENTS}

This manuscript is dedicated to the geologists and Earth scientists who have died in the course of their work. The author thanks several readers for their comments on early drafts, including MFS, JKW, OTLB, CYC, LMN, and LCB. Cedric John and James R. Metcalf provided helpful reviews. Thanks to Jeong-Hyun Lee and Jenn Pickering for editorial handling.

\section{STATEMENT}

This manuscript discusses suicide as a cause of death. In the US, the National Suicide Prevention Lifeline's phone number is 1-800-273-8255. Crisis Text Line can be reached by texting HOME to 741741 (US), 686868 (Canada), or 85258 (UK). Listeners are available at these numbers for those in crisis or those looking to help someone else.

\section{Copyright notice}

(CThe Author(s) 2021. This article is distributed under the terms of the Creative Commons Attribution 4.0 International License.

\section{Literature Cited}

Abeyta, A., Fernandes, A. M., Mahon, R., and Swanson, T. (2021). The true cost of fieldwork is a barrier to diversifying geosciences. https: //eartharxiv.org/repository/view/2091/.

Anadu, J., Ali, H., and Jackson, C. (2021). Ten steps to protect BIPOC scholars in the field. Eos, 101. https://doi.org/10.1029/2020EO150525. Asher, P. (2001). Teaching an introductory physical geology course to a student with visual impairment. Journal of Geoscience Education, 49(2):166169.

Bernard, R. E. and Cooperdock, E. H. G. (2018). No progress on diversity in 40 years. Nature Geoscience, 11(5):292-295.

Blackwell, E. and Pinder, P. (2014). What are the motivational factors of first-generation minority college students who overcome their family histories to pursue higher education? College Student Journal, 48(1):4556.

Brown, S. K., Jenkins, S. F., Sparks, R. S. J., Odbert, H., and Auker, M. R. (2017). Volcanic fatalities database: analysis of volcanic threat with distance and victim classification. Journal of Applied Volcanology, 6(1). 
Bureau of Labor Statistics (2019). All worker profile, 2003-2018. https: //www.bls.gov/iif/oshwc/cfoi/all worker.xlsx.

Bureau of Labor Statistics (2020). Census of Fatal Occupational Injuries: 2019. https://www.bls.gov/iif/oshcfoi1.htm.

Clancy, K. B., Nelson, R. G., Rutherford, J. N., and Hinde, K. (2014). Survey of Academic Field Experiences (SAFE): Trainees report harassment and assault. PLoS ONE, 9(7):1-9.

Conniff, R. (2021). Wall of the Dead: A Memorial to Fallen Naturalists. https://strangebehaviors.wordpress.com/2011/01/14/ the-wall-of-the-dead/. Accessed July 2021. Archived copy at https: //perma.cc/UX9C-AFK5.

Cooper, M. D. (2000). Towards a model of safety culture. Safety Science, 36(2):111-136.

Cooperdock, E. H. G., Chen, C. Y., Guevara, V. E., and Metcalf, J. R. (2021). Counteracting Systemic Bias in the Lab, Field, and Classroom. AGU Advances, 2(1):1-5.

da Silva Cardoso, E., Dutta, A., Chiu, C.-Y., Johnson, E. T., Kundu, M., and Chan, F. (2013). Social-cognitive predictors of STEM career interests and goal persistence in college students with disabilities from racial and ethnic minority backgrounds. Rehabilitation Research, Policy, and Education, 27(4):271-284.

Drummond, C. N. and Markin, J. M. (2008). An analysis of the Bachelor of Science in geology degree as offered in the United States. Journal of Geoscience Education, 56(2):113-119.

Duffy, R. D., Blustein, D. L., Diemer, M. A., and Autin, K. L. (2016). The psychology of working theory. Journal of Counseling Psychology, 63(2):127.

Easterling, W. E. (2020). Dear Colleague Letter: Geoscience Opportunities for Leadership in Diversity - Expanding the Network (GOLD-EN). https://www.nsf.gov/pubs/2020/nsf20058/nsf20058.jsp.

Ernst, W., Manduca, C., and Mogk, D. (2006). Geologic mapping-Where the rubber meets the road. Special Papers-Geological Society of America, 413:13.

Feig, A. D. (2010). Technology, accuracy and scientific thought in field camp: An ethnographic study. Journal of Geoscience Education, 58(4):240251.

Geikie, A. (1891). Outlines of Field-Geology. Macmillan.

Giles, S., Jackson, C., and Stephen, N. (2020). Barriers to fieldwork in undergraduate geoscience degrees. Nature Reviews Earth and Environment, $1(2): 77-78$

Greene, S., Ashley, K., Dunne, E., Edgar, K., Giles, S., and Hanson, E. (2020). Toilet stops in the field: An educational primer and recommended best practices for field-based teaching. https://osf.io/gnhj2/.

Hersch, J. (1998). Compensating differentials for gender-specific job injury risks. The American Economic Review, 88(3):598-607.

Himus, G. W., Sweeting, G. S., and Sweeting, M. M. (1955). Elements of Field Geology. University Tutorial Press.

John, C. M. and Khan, S. B. (2018). Mental health in the field. Nature Geoscience, 11(9):618-620.

Kingsbury, C. G., Sibert, E. C., Killingback, Z., and Atchison, C. L. (2020). "Nothing about us without us:" The perspectives of autistic geoscientists on inclusive instructional practices in geoscience education. Journal of Geoscience Education, 68(4):302-310.

Kudrenko, S., Ordiz, A., Barysheva, S. L., Baskin, L., and Swenson, J. E. (2020). Human injuries and fatalities caused by brown bears in Russia, 1932-2017. Wildlife Biology, 2020(1).

Lab Safety Institute (2021). Memorial Wall - Laboratory Safety Institute. https://www.labsafety.org/memorial-wall. Accessed July 2021. Archived copy at https://perma.cc/M47M-VZGA.

Leeth, J. D. and Ruser, J. (2006). Safety segregation: The importance of gender, race, and ethnicity on workplace risk. Journal of Economic Inequality, 4(2):123-152.

Liang, Y., Yin, J., Pan, B., Chi, G., Andris, C., Miller, Z., Jorgenson, J., and Nickerson, N. (2020). Understanding Demographics and Experience of Tourists in Yellowstone National Park through Social Media. Travel and Tourism Research Association: Advancing Tourism Research Globally. https://scholarworks.umass.edu/ttra/2020/research_papers/54/.

Ma, Y., Huang, G., and Autin, K. L. (2021). Linking decent work with academic engagement and satisfaction among first-generation college students: A psychology of working perspective. Journal of Career Assessment, 29(1):148-163.

Mol, L. and Atchison, C. (2019). Image is everything: educator aware- ness of perceived barriers for students with physical disabilities in geoscience degree programs. Journal of Geography in Higher Education, 43(4):544-567.

National Parks Service (2017). NPS Servicewide CY2014-CY2016 Mortality Dashboard. https://www.nps.gov/orgs/1336/data.htm\#closeout.

Occupational Safety and Health Administration (2021). Fatality and Catastrophe Investigation Summaries. https://www.osha.gov/pls/ imis/accidentsearch.html. Accessed July 2021.

Pacific Consulting Group (2019). National Park System 2019 Visitor Survey Card Data Report. Technical report, National Parks Service, US Department of the Interior. https://irma.nps.gov/DataStore/Reference/ Profile/2267716.

Petcovic, H. L., Stokes, A., and Caulkins, J. L. (2014). Geoscientists' perceptions of the value of undergraduate field education. GSA Today, 24(7):4-10.

Phillips, S. P. (2006). Risky business: explaining the gender gap in longevity. Journal of Men's Health and Gender, 3(1):43-46.

Schussman, L. C., Lutz, L. J., Shaw, R. R., and Bohnn, C. R. (1990). The epidemiology of mountaineering and rock climbing accidents. Journal of Wilderness Medicine, 1(4):235-248.

Stokes, A., Feig, A. D., Atchison, C. L., and Gilley, B. (2019). Making geoscience fieldwork inclusive and accessible for students with disabilities. Geosphere, 15(6):1809-1825.

Stokes, P. J., Levine, R., and Flessa, K. W. (2015). Choosing the geoscience major: Important factors, race/ethnicity, and gender. Journal of Geoscience Education, 63(3):250-263.

Tewksbury, B. and Tewksbury, D. (2004). Playing It Safe: Recognizing and Managing Risk When Working With Students in the Field. https: //nagt.org/nagt/teaching resources/field/safety/index.html.

Tieken, M. C. (2016). College talk and the rural economy: Shaping the educational aspirations of rural, first-generation students. Peabody Journal of Education, 91(2):203-223.

Wilson, C. (2019). Status of the Geoscience Workforce 2018. American Geosciences Institute.

Zavala, E. (2014). Encouragers and barriers that influence advanced degrees among first-generation Latino/a college students. PhD thesis, The Claremont Graduate University. 